\title{
Photovoltaic Supplied T-Type Three- Phase Inverter with Harmonic Current Compensation Capability
}

\author{
Zahera Batool \\ European University of Lefke (Cyprus) \\ Samet Biricik \\ Near East University - N.Cyprus, samet@biricikelektrik.com \\ Hasan Komurcugil \\ Eastern Mediterranean University - Cyprus
}

See next page for additional authors

Follow this and additional works at: https://arrow.tudublin.ie/engscheleart

Part of the Power and Energy Commons

\section{Recommended Citation}

Z. Batool, S. Biricik, H. Komurcugil, T. Ngo and T. V. Vu, "Photovoltaic Supplied T-Type Three- Phase Inverter with Harmonic Current Compensation Capability," 2019 2nd International Conference on Smart Grid and Renewable Energy (SGRE), 2019, pp. 1-5, doi: 10.1109/SGRE46976.2019.9020673.

This Conference Paper is brought to you for free and open access by the School of Electrical and Electronic Engineering at ARROW@TU Dublin. It has been accepted for inclusion in Conference papers by an authorized administrator of ARROW@TU Dublin. For more information, please contact arrow.admin@tudublin.ie, aisling.coyne@tudublin.ie,gerard.connolly@tudublin.ie.

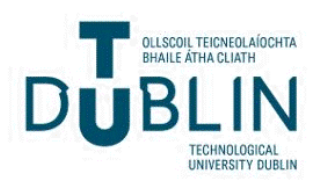




\section{Authors}

Zahera Batool, Samet Biricik, Hasan Komurcugil, Tuan Ngo, and Tuyen V. Vu

This conference paper is available at ARROW@TU Dublin: https://arrow.tudublin.ie/engscheleart/335 


\title{
Photovoltaic Supplied T-Type Three-Phase Inverter with Harmonic Current Compensation Capability
}

\author{
Zahera Batool ${ }^{\mathrm{a}}$, Samet Biricik ${ }^{\mathrm{a}, \mathrm{b}}$, Hasan Komurcugil ${ }^{\mathrm{c}}$, Tuan Ngo ${ }^{\mathrm{d}}$, Tuyen V. Vu ${ }^{\mathrm{e}}$ \\ ${ }^{\text {a }}$ Department of Electrical and Electronics Eng., European University of Lefke, Lefke, Northern Cyprus TR-10 Mersin, Turkey \\ ${ }^{b}$ School of Electrical and Electronic Engineering, Technological University Dublin, Dublin, Ireland \\ ${ }^{\mathrm{c}}$ Department of Computer Engineering, Eastern Mediterranean University, Famagusta, Northern Cyprus TR-10 Mersin, Turkey \\ ${ }^{\mathrm{d}}$ Electric Power Engineers, Inc. Texas, Austin, USA \\ eElectrical and Computer Engineering Department, Clarkson University Potsdam, NY, USA \\ sbiricik@eul.edu.tr, zahera.batool133@yahoo.com, hasan.komurcugil@emu.edu.tr, ngotuan@utexas.edu, tvu@clarkson.edu
}

\begin{abstract}
In this paper, a T-Type grid-connected inverter with harmonic current compensation capability is proposed and studied for the on-grid photovoltaic (PV) systems. This idea is based on the modification of the existing photovoltaic inverter control algorithm with the adaptation of active power filter control algorithm. The grid-connected PV inverter has similar topology and control methods as that of the active power filter systems. However, such multifunctional inverters have not yet matured for commercial use and call for more research. In this work, a conventional phase locked-loop algorithm is used to determine the angular position of the synchronous reference of the grid voltages. PV power is estimated and fed into the control loop. Then, the measured currents at the load terminals are proceeded to obtain harmonic current components. The obtained control signals are used to drive the grid-connected T-Type inverter.
\end{abstract}

Keywords-Multifunctional Inverters, T-Type NPC inverter, Active Power Filter future.

\section{INTRODUCTION}

It is well known that power quality has become a major issue in the power industry due to the integration of power electronics equipment into the utility. Nonlinear products may cause current and voltage distortion. As well known that, if the harmonic distortion is sufficiently large, various electrical failures may occur, such as transformer overheating, power capacitors failure, neutral current anomalies, and a low power factor, which may occur in supplier and consumer electrical system [1]. To overcome these issues, various custom power devices such as active power filter (APF) topologies along with control methods have been investigated by the researchers and these solutions have been placed on the industrial market as a reachable product. Although the APFs are adopted in the airports, hospitals, industries, etc., they are not a preferred solution for the low power consumers due to high cost. In addition, due to the cost of such systems the commercial use of custom power devices is highly limited.
On the other hand, the use of grid-connected PV systems is increased significantly over the last decades. In general, The grid-connected PV inverter has similar topology and control methods as that of the active power filter systems. Therefore, the idea of operating a PV inverter with an additional function as a custom power device has been proposed recently and this inverter is called a multifunctional inverter. This idea was first presented in [2] for power factor improvement. In [3], a method is proposed to support reactive power from PV groups to the single-phase system. The PV-APF combination of three-phase three-wire system is studied in [4]. Initially, these combinations are verified by using classical two-level inverters. With the increasing attention to multilevel inverters, several multilevel configurations have been proposed over the last twenty years. The most popular are the flying capacitor [5], diode-clamped neutral-point clamped converter (NPC) [6], cascaded H-bridge [7], PUC Converters [8] and T-Type structures [9]. Each of these structures has its own advantages and disadvantages. One aspect which sets the T-Type inverter structure apart from other multilevel inverters is that they do not require clamping diodes. The T-type inverter is a new multilevel inverter topology, has been applied for many applications such as induction machine drives [10] and grid-connected inverters [9].

In this work, a T-type grid-connected inverter with additional function is studied for PV applications to reduce the effects of produced harmonic current distortions by the consumer's nonlinear products.

\section{THE T-TYPE THREE-PHASE TOPOLOGY}

In the T-type inverter topology, there are two different forms of bidirectional switch configuration. The bidirectional switches can be connected either in common-collector configuration or in the common-emitter configuration. In this study, the common-emitter configuration is used as illustrated in Fig. 1, For the implementation of the T-type converter, the upper and the lower-side switches $S_{l a}$ and $S_{4 a}, S_{l b}$ and $S_{4 b}, S_{l c}$ and $S_{4 c}$ have selected at the higher voltage level from the dc link voltage since the dc link voltage has to be blocked by those switches. However, the bidirectional switches at the midpoint 
of the split dc sources must block only half of the dc link voltage. Therefore, lower voltage rated swathes can be used. The reduced blocking voltage at the bidirectional switches causes to reduce the switching losses although there are two switches connected in series. This is the most important difference in the T-type configuration from the three-level NPC topology. Simply, in the NPC configuration, the seriesconnected switches must block the whole dc-link voltage. The efficiency analysis of T-type, NPC and conventional 2-level inverter is reported by Johann W. Kolar in [11]. The power electronics researchers have developed the NPC inverters for the medium voltage applications. This is the main reason to connect switches series to increase the voltage blocking capacity of the converter because IGBT technology is limited with 1600/1700 V blocking voltage. Although the NPC topology has many advantages, increasing blocking voltage by series-connected of IGBTs is not necessary for the low voltage application. Therefore, the T-type topology is the better choice for low-voltage applications based on bipolar devices.

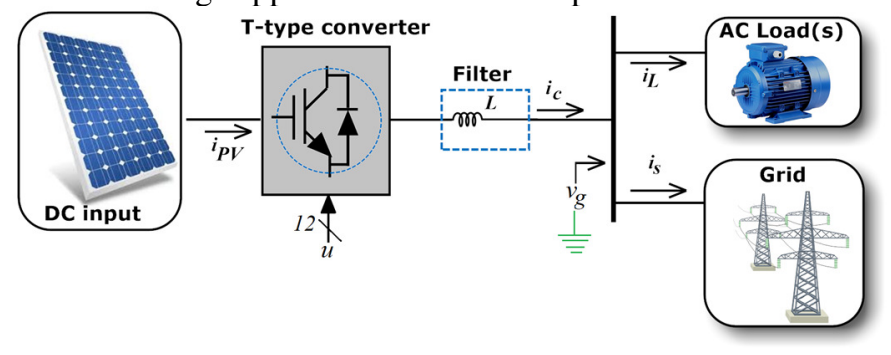

(a)

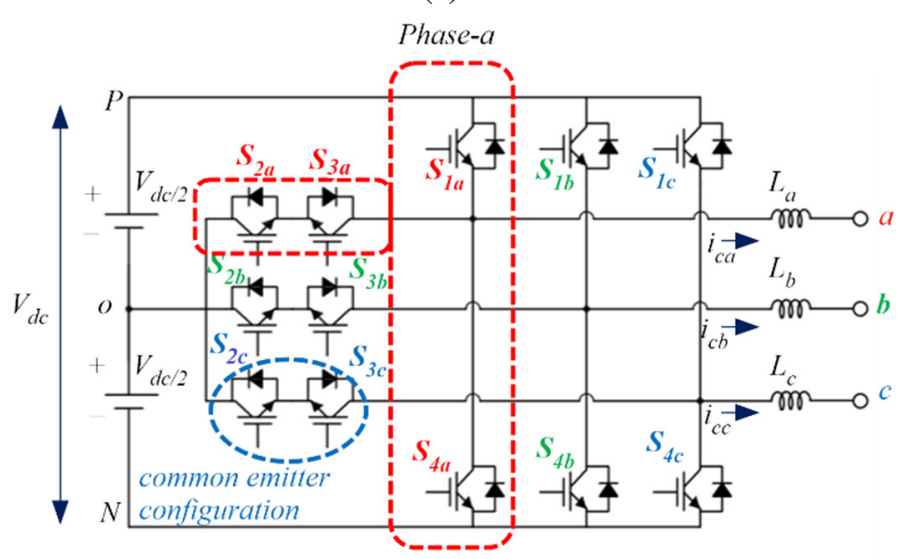

(b)

Fig. 1. Studied T-type converter (a) grid interface (b) topology

\section{COMBINED CONTROLLER}

The block diagram of the studied control method is shown in Fig. 2. The harvested power from the photovoltaic groups is assumed to feed the dc-link capacitor of the T-type inverter by using an appropriate MPPT algorithm. The operation of the MPPT and DC-DC converter is not discussed in this study. In order to split evenly the harvested power in each line (phase), the solar power $P_{P V}$ is divided equally into 3 amounts. Therefore, the injected current equations in terms of the peak value can be written as

$$
\begin{gathered}
\bar{i}_{p v_{-} a}(t)=\frac{P_{P V} / 3}{V_{s a}} \cdot \sin \theta \\
\bar{i}_{p v_{-} b}(t)=\frac{P_{P V} / 3}{V_{s b}} \cdot \sin \left(\theta-\frac{2 \pi}{3}\right) \\
\bar{i}_{p v_{-} c}(t)=\frac{P_{P V} / 3}{V_{s c}} \cdot \sin \left(\theta+\frac{2 \pi}{3}\right)
\end{gathered}
$$

The grid frequency is determined by using a phase-locked loop (PLL) algorithm to obtain the angular position. Then, the obtained current waveforms in (1) are converted into the $d q$ frame as

$$
\begin{aligned}
& {\left[\begin{array}{l}
\bar{i}_{p v_{-} d}(t) \\
\bar{i}_{p v_{-} q}(t)
\end{array}\right]} \\
& =\sqrt{\frac{2}{3}}\left[\begin{array}{ccc}
\cos \theta & \sin \left(\theta-\frac{2 \pi}{3}\right) & \cos \left(\theta+\frac{2 \pi}{3}\right) \\
-\sin \theta & -\sin \left(\theta-\frac{2 \pi}{3}\right) & -\sin \left(\theta+\frac{2 \pi}{3}\right)
\end{array}\right] \cdot\left[\begin{array}{c}
\bar{i}_{p v_{-} a}(t) \\
\bar{i}_{p v_{-} b}(t) \\
\bar{i}_{p v_{-} c}(t)
\end{array}\right]
\end{aligned}
$$

Since our aim is the blocking of current harmonic injection to the grid, the measured load currents $\left(i_{L a}(t), i_{L b}(t), i_{L c}(t)\right)$, are first converted into the synchronous rotating $d q$ frame as shown below

$$
\begin{aligned}
& {\left[\begin{array}{l}
i_{L d}(t) \\
i_{L q}(t)
\end{array}\right]} \\
& =\sqrt{\frac{2}{3}}\left[\begin{array}{ccc}
\cos \theta & \sin \left(\theta-\frac{2 \pi}{3}\right) & \cos \left(\theta+\frac{2 \pi}{3}\right) \\
-\sin \theta & -\sin \left(\theta-\frac{2 \pi}{3}\right) & -\sin \left(\theta+\frac{2 \pi}{3}\right)
\end{array}\right] \cdot\left[\begin{array}{l}
i_{L a}(t) \\
i_{L b}(t) \\
i_{L c}(t)
\end{array}\right]
\end{aligned}
$$

In the case of non-linear load use, the load currents may consist of harmonic currents. In this work, the fundamental components of the load currents $\left(\bar{i}_{L d}(t), \bar{i}_{L q}(t)\right)$ are obtained by using the Self-tuning Filter.

$$
\begin{aligned}
& \bar{i}_{L d}(s)=\frac{k}{s}\left[i_{L d}(s)-\bar{i}_{L d}(s)\right]-\frac{\omega}{s} \bar{i}_{L q}(s) \\
& \bar{i}_{L q}(s)=\frac{k}{s}\left[i_{L q}(s)-\bar{i}_{L q}(s)\right]+\frac{\omega}{s} \bar{i}_{L d}(s)
\end{aligned}
$$

Then, the harmonic components of load currents are obtained as a subtraction of the current value and measured load current as below

$$
\begin{aligned}
& \tilde{\imath}_{L d}(t)=i_{L d}(t)-\bar{i}_{L d}(t) \\
& \tilde{\imath}_{L q}(t)=i_{L q}(t)-\bar{i}_{L q}(t)
\end{aligned}
$$

Hence, the addition of (2) with (5) is given to required reference converter current which achieves the current harmonic suppression and also supports harvested PV power as follows

$$
\begin{gathered}
i_{c d}^{*}(t)=\bar{i}_{p v_{-} d}(t)+\tilde{i}_{L d}(t) \\
i_{c q}^{*}(t)=\bar{i}_{p v_{-} d}(t)+\tilde{i}_{L q}(t)
\end{gathered}
$$

The converter references in (6) are then converted into the three-phase $a b c$-reference waveforms using the following inverse synchronous transform

$$
\left[\begin{array}{l}
i_{c a}^{*}(t) \\
i_{c b}^{*}(t) \\
i_{c c}^{*}(t)
\end{array}\right]=\sqrt{\frac{2}{3}}\left[\begin{array}{cc}
\cos \theta & -\sin \theta \\
\cos \left(\theta-\frac{2 \pi}{3}\right) & -\sin \left(\theta-\frac{2 \pi}{3}\right) \\
\cos \left(\theta+\frac{2 \pi}{3}\right) & \sin \left(\theta+\frac{2 \pi}{3}\right)
\end{array}\right] \cdot\left[\begin{array}{l}
i_{c d}^{*}(t) \\
i_{c q}^{*}(t)
\end{array}\right]
$$




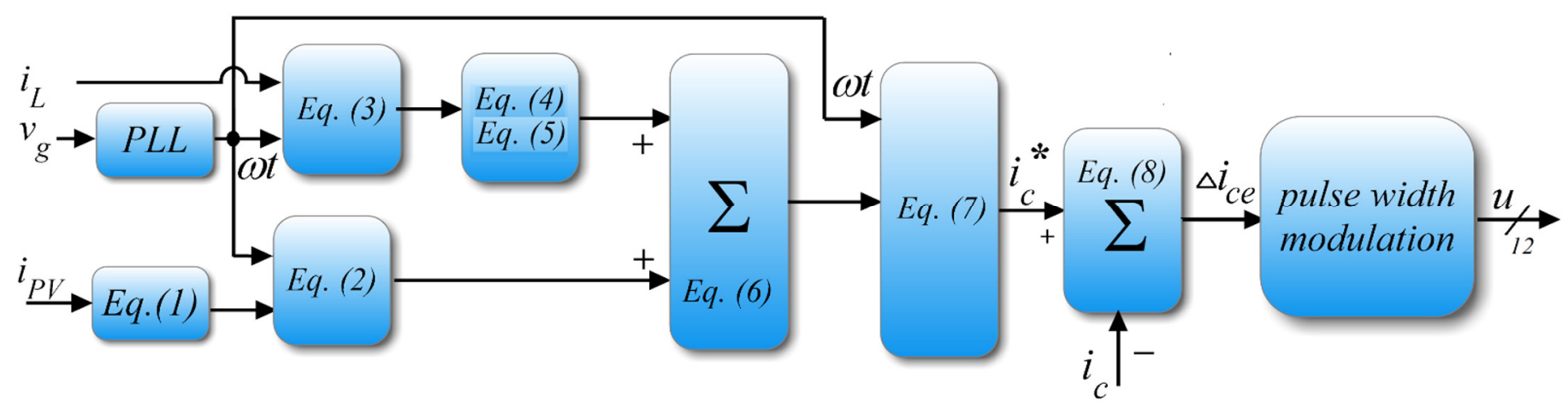

Fig. 2. The studied combined controller for the T-Type Three-Phase Inverter

Finally, the converter current errors, $\Delta i_{c}$, can be obtained by subtracting the measured converter currents, $i_{c}$, from their reference, $i_{c}^{*}$, as follows

$$
\Delta i_{c k}(t)=i_{c k}^{*}(t)-i_{c k}(t) \quad k=a, b, c .
$$

The inverter current error of each phase is used to drive the Ttype Three-Phase Inverter switches.

To observe the performance of the studied method, Matlab/Simulink simulations have been carried out which are presented and discussed in the following section.

\section{Simulation RESUltS}

The studied system is simulated in MATLAB/Simulink environment to verify the performance of the proposed techniques. In this model, the three-phase line-to-line source voltage is assumed to be $400 \mathrm{~V}$. A resistive load is used as a linear load and a full bridge rectifier supplied RL load is used as a nonlinear load. The system and control parameters used in this study are given in Table I.

TABLE I

PARAMETERS OF THE SIMULATED SYSTEM

\begin{tabular}{|c|c|c|}
\hline Symbol & Quantity & Value \\
\hline $\mathrm{v}_{\mathrm{S},} f$ & Phase to Neutral Volt. \& Freq. & $230 \mathrm{~V}, 50 \mathrm{~Hz}$ \\
\hline$L_{c}$ & Converter Filter Impedance & $1.95 \mathrm{mH}$ \\
\hline $\mathrm{Z}_{\mathrm{L}}$ & Load Impedance & $1 \mathrm{~m} \Omega 0.3 \mathrm{mH}$ \\
\hline Load $_{1}$ & Linear Load Resistance & $\begin{array}{c}3 \times 20 \Omega \\
\text { (Y-connected) }\end{array}$ \\
\hline Load $_{2}$ & Non-Linear Load Res. and Ind. & $30 \Omega, 30 \mathrm{mH}$ \\
\hline$V_{d c}$ & dc- Link voltage & $750 \mathrm{~V}$ \\
\hline$\gamma$ & STF Gain & 40 \\
\hline
\end{tabular}

In order to see the behavior of the analyzed system load groups, the simulation is run up to $0.25 \mathrm{sec}$ while the inverter is off and results are presented in Fig. 3. The total harmonic distortion (THD) of the non-linear load current is computed as $28.66 \%$. The loads are turned off from 0 to $0.05 \mathrm{sec}$ since there is no power production by the PV panels in this case (See Fig.3(b)). After $0.05 \mathrm{sec}$, the resistive load (linear-load) is turned ON and current at the load bus is increased to $11.48 \mathrm{~A}$ without harmonic pollution. After 0.1 seconds the linear load is turned off and non-linear load is turned on up to 0.2 seconds. During this period, the harmonic pollution is increasing to 28.66 $\%$ at the load bus while the load current is $13.88 \mathrm{~A}$. After the period 0.2 seconds all loads turned off.

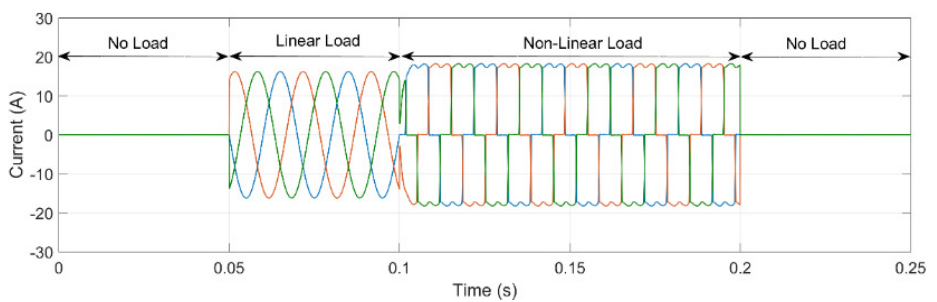

(a)

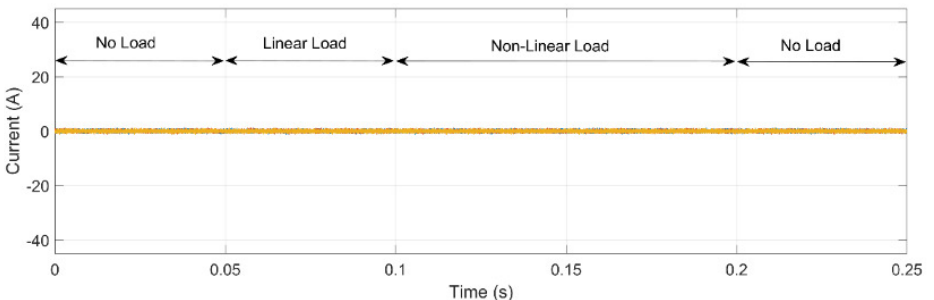

(b)

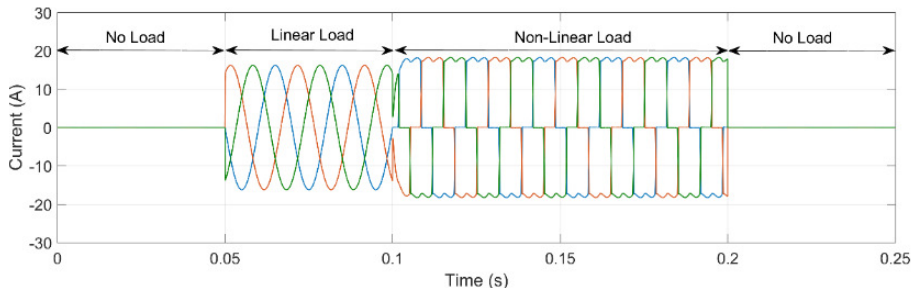

(c)

Fig. 3. Simulated response of the proposed system during inverter off: (a) Load currents, (b) Inverter currents (c) Grid currents

As shown in Fig. 4 the system is operated with on-grid inverter but without harmonic compensation, capability as commonly used in the PV market. Under this condition, once more the system is simulated up to $0.25 \mathrm{sec}$. As can be seen in Fig. 4 (a), the loads are off between 0 to 0.05 sec. During this period, the power at the dc link of the inverter is injected into the grid as can be seen in Fig. 4 (b) between 0-0.05sec. The current in phase-a, phase- $\mathrm{b}$ and phase-c are measured as 46 A with 0.88 $\%$ harmonic distortion. After the period from 0.05 to 0.1 
seconds where the resistive load is energized a certain amount of injected power by the inverter is fed the load and the rest of the power is directed to the grid.

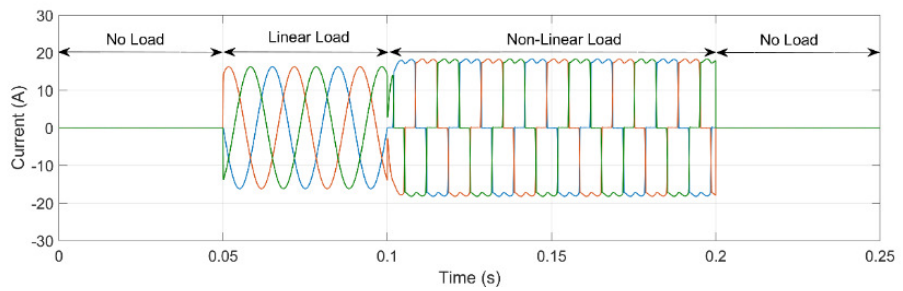

(a)

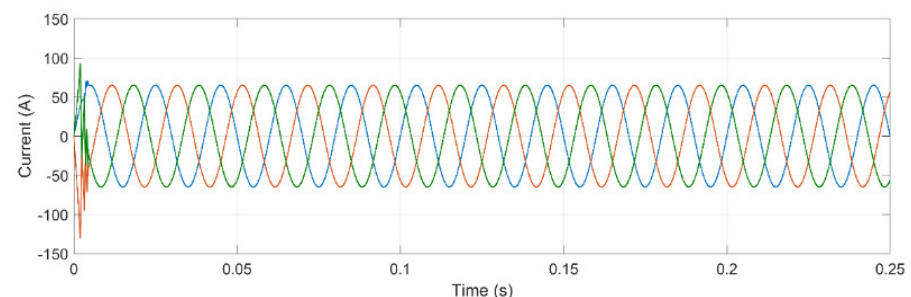

(b)

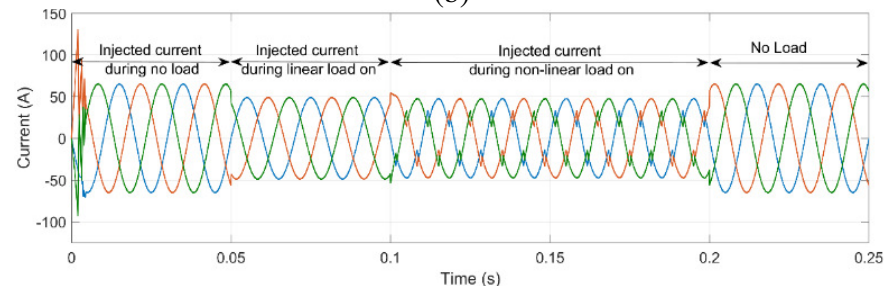

(c)

Fig. 4. Simulated response of the proposed system during inverter on but without harmonic compensation capability: (a) Load currents, (b) Inverter currents (c) Grid currents.

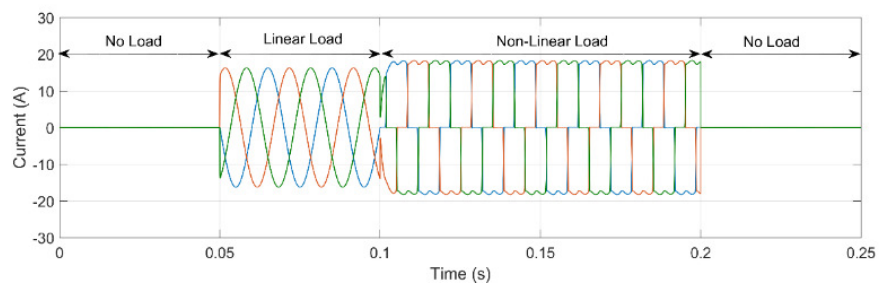

(a)

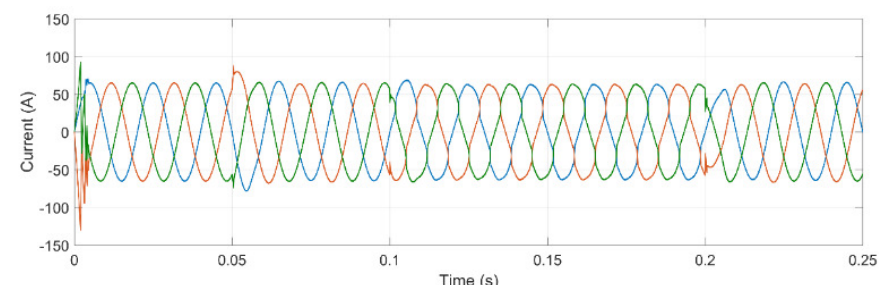

(b)

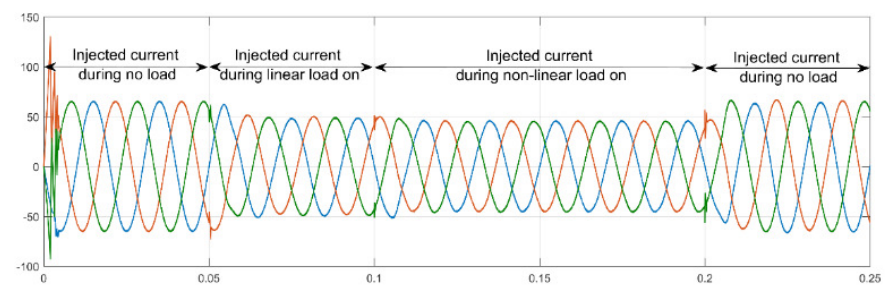

(c)

Fig. 5. Simulated response of the proposed system during inverter $\mathrm{ON}$ with harmonic compensation capability: (a) Load currents, (b) Inverter currents (c) Grid currents.
In this case, the THD on the grid side is measured as 1.12 and the line currents are $34.48 \mathrm{~A}$ at the grid side. After turning off the linear load and turning on the non-linear load the grid current is measured as 32.27 A with $12.11 \%$ harmonic pollution. It is clear that the harmonic pollution caused by the load side is reflected on the grid side. After the adaptation of the proposed controller into the T-type inverter controller, the distortion at the grid side is reduced up to $1.36 \%$ (See Fig. 5(c). Fig. 5 (b) clearly shows that the grid-connected PV inverter is behaved as an active power filter during pushing the converted power by the inverter.

\section{CONCLUSIONS}

In this study, a two-leg three-phase T-type inverter topology is investigated for active power filter applications. A self-tuning filter technique is used to generate reference load current. Moreover, the capacitor voltage balancing strategy is proposed. In order to reduce the switching frequency, the three-level hysteresis band controller is proposed. The performance of the studied system is investigated by simulation study during steady-state and varying load conditions. The presented results show that the harmonic distortions are eliminated successfully with the proposed topology and control method.

\section{REFERENCES}

[1] W. M. Grady and S. Santoso, "Understanding Power System Harmonics," in IEEE Power Engineering Review, vol. 21, no. 11, pp. 8-11, Nov. 2001. doi: 10.1109/MPER.2001.961997

[2] S. Kim, Gwonjong Yoo and Jinsoo Song, "A bifunctional utility connected photovoltaic system with power factor correction and UPS facility," Conference Record of the Twenty Fifth IEEE Photovoltaic Specialists Conference - 1996, Washington, DC, USA, 1996, pp. 13631368.doi: 10.1109/PVSC.1996.564386

[3] C. Chang, Y. Lin, Y. Chen and Y. Chang, "Simplified Reactive Power Control for Single-Phase Grid-Connected Photovoltaic Inverters," in IEEE Transactions on Industrial Electronics, vol. 61, no. 5, pp. 2286-2296, May 2014. doi: 10.1109/TIE.2013.2271600

[4] N. D. Tuyen and G. Fujita, "PV-Active Power Filter Combination Supplies Power to Nonlinear Load and Compensates Utility Current," in IEEE Power and Energy Technology Systems Journal, vol. 2, no. 1, pp. 32-42, March 2015. doi: 10.1109/JPETS.2015.2404355

[5] Y. P. Siwakoti and F. Blaabjerg, "A novel flying capacitor transformerless inverter for single-phase grid connected solar photovoltaic system," 2016 IEEE 7th International Symposium on Power Electronics for Distributed Generation Systems (PEDG), Vancouver, $\quad$ BC, 2016, pp. 1-6. doi: 10.1109/PEDG.2016.7527086

[6] M. Schaefer, W. Goetze, M. Hofmann, F. Bayer, D. MontesinosMiracle and A. Ackva, "Direct Current Control for Grid-Connected 
Diode-Clamped Inverters," in IEEE Transactions on Industrial Electronics, vol. 64, no. 4, pp. 3067-3074, April 2017. doi: 10.1109/TIE.2016.2636127

[7] B. Xiao, L. Hang, J. Mei, C. Riley, L. M. Tolbert and B. Ozpineci, "Modular Cascaded H-Bridge Multilevel PV Inverter With Distributed MPPT for Grid-Connected Applications," in IEEE Transactions on Industry Applications, vol. 51, no. 2, pp. 1722-1731, March-April 2015. doi: 10.1109/TIA.2014.2354396

[8] S. Biricik and H. Komurcugil, "Proportional-Integral and Proportional-Resonant Based Control Strategy for PUC Inverters," IECON 2018 - 44th Annual Conference of the IEEE Industrial Electronics Society, Washington, DC, 2018, pp. 3369-3373. doi: 10.1109/IECON.2018.8591371
[9] N. Altin, S. Ozdemir, H. Komurcugil, I. Sefa and S. Biricik, "Sliding-Mode and Proportional-Resonant Based Control Strategy for Three-Phase Two-Leg T - Type Grid-Connected Inverters with LCL Filter," IECON 2018 - 44th Annual Conference of the IEEE Industrial Electronics Society, Washington, DC, 2018, pp. 4492-4497. doi: 10.1109/IECON.2018.8591542

[10] D. Lee and Y. Kim, "Control of Single-Phase-to-Three-Phase AC/DC/AC PWM Converters for Induction Motor Drives," in IEEE Transactions on Industrial Electronics, vol. 54, no. 2, pp. 797-804, April 2007. doi: 10.1109/TIE.2007.891780

[11] M. Schweizer and J. W. Kolar, "Design and Implementation of a Highly Efficient Three-Level T-Type Converter for Low-Voltage Applications," in IEEE Transactions on Power Electronics, vol. 28, no. 2, pp. 899-907, Feb. 2013. doi: 10.1109/TPEL.2012.2203151 